\title{
Penerapan Metode Analytical Hierarchy Process (AHP) dalam Perekrutan Petugas Keamanan
}

\author{
Yustria Handika Siregar¹, Muhammad Dedi Irawan², Agung Hazarin Aulia Chaniago ${ }^{3}$ \\ ${ }^{1,3}$ Teknik Informatika, Universitas Asahan, Jalan Ahmad Yani Kisaran, Indonesia \\ e-mail: 1yustria.siregar@gmail.com, ${ }^{3}$ cagung988@gmail.com
}

${ }^{2}$ Sistem Informasi, Universitas Negeri Islam Sumatera Utara, Jalan Williem Iskandar Medan, Indonesia e-mail: ${ }^{2}$ muhammaddediirawan @uinsu.ac.id

Submitted Date: September $08^{\text {th }}, 2020$ Revised Date: September $28^{\text {th }}, 2020$
Reviewed Date: September 22 $2^{\text {nd }}, 2020$

Accepted Date: September $30^{\text {th }}$, 2020

\begin{abstract}
The security category does not escape a strict security system. The Security Task Force (SATGASKAM) is a unit that guards every agency and company in order to avoid crime. There were several problems in the security unit recruitment process. This applies a conventional assessment. It is said to be conventional because the assessment system in the recruitment only involves human reasoning abilities from a number of predetermined criteria. In this study, the Analytical Hierarchy Process (AHP) method was applied for the security guard recruitment system. The selection process uses criteria which are the requirements for being accepted as security officers. The criteria used are the level of education, the equality value, the psychological score, and the results of the interviews. These criteria include the requirements contained in the regulation of the Head of Police of the Republic of Indonesia. The research method is carried out in several stages by comparing the AHP calculation process and the process of the result value of the system. The AHP process begins by determining the criteria, the eigenvalues. The results of the AHP method show transparency in recruitment with respective values and have a certain weight according to the priority of the agency.
\end{abstract}

Keywords: AHP; Recruitment; Security Officer

\section{Abstrak}

Kategori keamanan tidak luput dari sistem keamanan yang ketat. Satuan Tugas Keamanan (SATGASKAM) merupakan unit yang menjaga setiap instansi maupun perusahaan agar terhidar dari tindak kejahatan. Terdapat beberapa permasalahan dalam proses perekrutan satuan keamanan tersebut. Hal tersebut menerapkan penilaian secara konvensional. Dikatakan konvensional karena sistem penilaian dalam rekrutmen tersebut hanya melibatkan kemampuan nalar manusia dari beberapa kriteria yang sudah ditetapkan. Pada penelitian ini diterapkan metode Analytical Hierarchy Process (AHP) untuk sistem rekrutmen petugas keamanan. Proses seleksi digunakan kriteria-kriteria yang merupakan syarat diterima menjadi petugas keamanan. Kriteria yang digunakan adalah tingkat pendidikan, nilai kesapmataan, nilai psikotes dan hasil wawancara. Kriteria tersebut teramasuk syarat yang tertuang dalam peraturan Kepala Kepolisan Republik Indonesia. Metode penelitian dilaksanakan dengan beberapa tahapan dengan membandingkan proses perhitungan AHP dan proses nilai hasil dari sistem. Proses AHP dimulai dengan menentukan kriteria, nilai eigen. Hasil metode AHP menunjukkan transparansi dalam perekrutan dengan nilai-nilai masing-masing dan memiliki bobot tertentu sesuai prioritas dari pihak instansi.

Kata Kunci: AHP; Perekrutan; Petugas Keamanan 


\section{Pendahuluan}

Petugas keamanan atau sering disebut dengan SATGASKAM (Satuan Tugas Keamanan) memiliki peran yang sangat penting di mana pun. Bagian dari aparat keamanan dalam melaksanakan kewajiban dan komitmennya untuk membantu fungsi Polri terdekat dalam meramalkan adanya gangguan kejahatan atau apabila terjadi pelanggaran dan tindak pidana di lingkungan kerja, demikian pula aparat keamanan yang memiliki kapasitas dan pengetahuan dibutuhkan. Hal tersebut membutuhkan sistem pendaftaran yang layak dan benar.

Di Universitas Asahan, fungsi dan manfaat petugas keamanan menjadi salah satu hal yang sangat berpengaruh mengingat kegiatan di kampus ini setiap harinya melibatkan ratusan bahkan ribuan mahasiswa dari berbagai fakultas. Selain itu luasnya area kampus UNA juga membutuhkan perhatian yang serius menyangkut keamanan dan kenyamanan warganya. kemudahan akses untuk keluar masuk kampus merupakan salah satu faktor yang mempengaruhi keamanan di lingkungan kampus. Untuk itulah dibutuhkan petugas keamanan yang dapat memenuhi beberapa kriteria yang sesuai dengan lingkungan kampus.

Masalah sistem saat ini masih menerapkan penilaian secara konvensional. Dikatakan konvensional karena sistem penilaian dalam rekrutmen tersebut hanya melibatkan kemampuan nalar manusia dari beberapa kriteria yang sudah ditetapkan. Metode rekrutmen ini tak jarang juga disalahgunakan oleh oknum-oknum yang tidak bertanggungjawab untuk mengambil keuntungan pribadi. Hal ini dapat terjadi karena sistem perekrutan dan penilaian yang tidak transparan sehingga memungkinkan terjadinya KKN yaitu Korupsi, Kolusi dan Nepotisme. Dari sisi pengguna jasa pada umumnya perusahaan tidak dapat mengetahui secara detail, apakah kriteria yang diminta pihaknya sudah benar-benar terpenuhi atau tidak.

Penggunaan metode AHP telah dilakukan dalam penelitian dalam kasus rekrutmen dan seleksi. Namun beberapa rekrutmen dan seleksi diperuntuhkan pada karyawan dari berbagai perusahaan. Pada penelitian ini dilakukan dalam perekrutan petugas keamanan dapat digunakan metode yang sama. Sehingga permasalahan pada pihak kampus dalam perekrutan petugas keamanan yang bersistem dan terhindar dari $\mathrm{KKN}$ terlaksana dan transparan. Sumber data perekrutan mengacu pada Peraturan Kepala Kepolisian Republik Indonesia (Sutanto, 2007).

\section{Tinjauan Literatur}

Penerapan Analytical Hierarchy Process (AHP) pernah dilakukan dalam pemilihan karwayan baru dengan kriteria pengalaman kerja, rekomendasi, wawancara, penampilan dan keaadan fisik pada karyawan baru PT. Noreen Surya Perdana (Sasongko, Astuti, \& Maharani, 2017). Penelitian pemanfaatan AHP dalam penerimaan karyawan juga pernah digunakan dengan studi kasus : RB. Nilam Sari Tembilahan dengan kriteria pendidikan, performance, kemampuan berkomunikasi, motivasi dan antusiasme. Penelitian tersebut diimplementasikan pada pemrograman visual basic (Rianto, 2016). Penelitian dengan kasus yang sama namun memiliki studi kasus yang berbeda yaitu PT. VIRTUS VENTURAMA dengan memanfaatkan metode AHP dalam perekrutan karyawan. Kriteria yang digunakan attitude, pendidikan, performa, kemampuan berkomunikasi, sertifikasi kompetensi, motivasi dan antusiasme (Handayani \& Muzakir, 2018). Penelitian selanjutnya studi kasus pada karyawan UNICHARM INDONESIA dengan lima kriteria yaitu Usia, Pendidikan, Nilai IPK, Pengalaman dan Training/ Sertifikasi (Mutholib \& Febrina, 2017).

Pengguna melalui AHP pernah dilakukan dalam memberi peringkat pada indikator kinerja gedung dan risiko. Hasil pemeringkatan indeks dengan metode AHP. Sebanyak 12 ahli dan praktisi Manajemen Fasilitas terlibat dalam proses pemeringkatan. Pembobotan subjektif dianalisis dengan menggunakan program software komputer AHP Expert Choice 11. Hasil AHP berhasil memberikan skor pembobotan untuk semua indikator risiko kinerja, dengan lima indikator menempati peringkat paling kritis; stabilitas struktural (14,9\%), layanan pencegahan kebakaran $(9,1 \%)$, penyakit terkait bangunan $(7,4 \%)$, pintu keluar darurat $(6,8 \%)$, dan layanan listrik $(6,3 \%)$ (Khalil, Kamaruzzaman, \& Baharum, 2016).

AHP diperkenalkan dalam penelitian yang mendukung kontraktor dalam pemilihan mereka untuk metode tanpa parit yang paling tepat, dengan mempertimbangkan karakteristik proyek dan kondisi lokasi. Kerangka fitur melalui empat modul yang berbeda sebagai berikut: (1) Modul Input di mana pengguna memasukkan atribut proyek melalui antarmuka pengguna AHP-DSS. (2) Modul Database Pusat yang berisi metode trenchless yang dianggap, batasan atribut proyek dan bobotnya, serta metode trenchless dan skornya. (3) Mesin berbasis hierarki analitik yang berjalan secara 
bersamaan dengan modul database pusat untuk menyediakan pengguna dengan metode konstruksi yang paling sesuai. (4) Modul Metode Teknologi Trenchless yang menunjukkan metode paling sesuai yang sesuai dengan input pengguna yang telah ditentukan sebelumnya (Salah, Samra, \& Hosny, 2016).

Perangkingan menggunakan AHP pernah juga dilakukan dalam penentu keputusan pemilihan menu makanan bagi anak dengan kriteria yang tersedia dan menghasilkan nilai tertinggi pada makanan alternatif sup ayam (Siregar \& Rahayu, 2018).

AHP selanjutnya pernah juga diterapkan untuk mengetahui tekanan adopsi Green Supply Chain Management (GSCM) dan menentukan peringkat tekanan berdasarkan pendapat para ahli melalui teknik AHP dalam konteks industri pertambangan dan mineral. Dari hasil AHP bahwa industri pertambangan dan mineral perlu fokus pada praktik pengelolaan lingkungan secara serius. Tidak ada alternatif untuk meningkatkan kinerja lingkungan dari posisinya saat ini. Tetapi subjek membutuhkan analisis yang lebih rinci. Menganalisis dan mengidentifikasi tekanan penting untuk penerapan praktik GSCM sangat penting bagi manajer untuk semua departemen di industri (Mathiyazhagan, Diabat, Al-Refaie, \& Xu, 2015).

AHP pernah dikombinasi dengan metode Simple Additive Weighting (SAW) untuk pengolahan nilai peserta terkait pemilihan penyanyi terbaik sehingga perlu adanya mekanisme pendukung keputusan untuk dapat menemukan penyanyi terbaik. Kriteria yang digunakan untuk menganalisis tingkat konsistensi bobot prioritas memiliki hasil yang konsisten yang cukup untuk menentukan penyanyi terbaik berdasarkan semua alternatif yang tersedia. Berdasarkan hasil pengukuran ketelitian penggunaan metode dan pemilihan tim ahli diperoleh hasil yang baik dengan presentase ketelitian 84,61\% (Cahyapratama \& Sarno, 2018).

Penelitian lainnya yang menggabung AHP dan SAW untuk mencari alternatif terbaik. metode tersebut digunakan untuk mengambil keputusan terhadap calon nasabah yang mengajukan pinjaman. Berdasarkan hasil pengukuran didapat dengan presentase ketelitian 90,67\% (Harefa, 2020).

Penelitian metode AHP pernah digabungkan dengan metode konsitensi penuh (FUCOM) dalam satu sistem telah digunakan untuk menilai empat maskapai penerbangan Libya dengan mempertimbangkan lima bidang kinerja utama; keandalan maskapai, karyawan, manajemen, kepuasan pelanggan, dan bentuk nyata (Badi \& Abdulshahed, 2019).

\section{Metode Penelitian}

Urutan Eksperimen pada penelitian ini terlihat pada gambar di bawah ini:

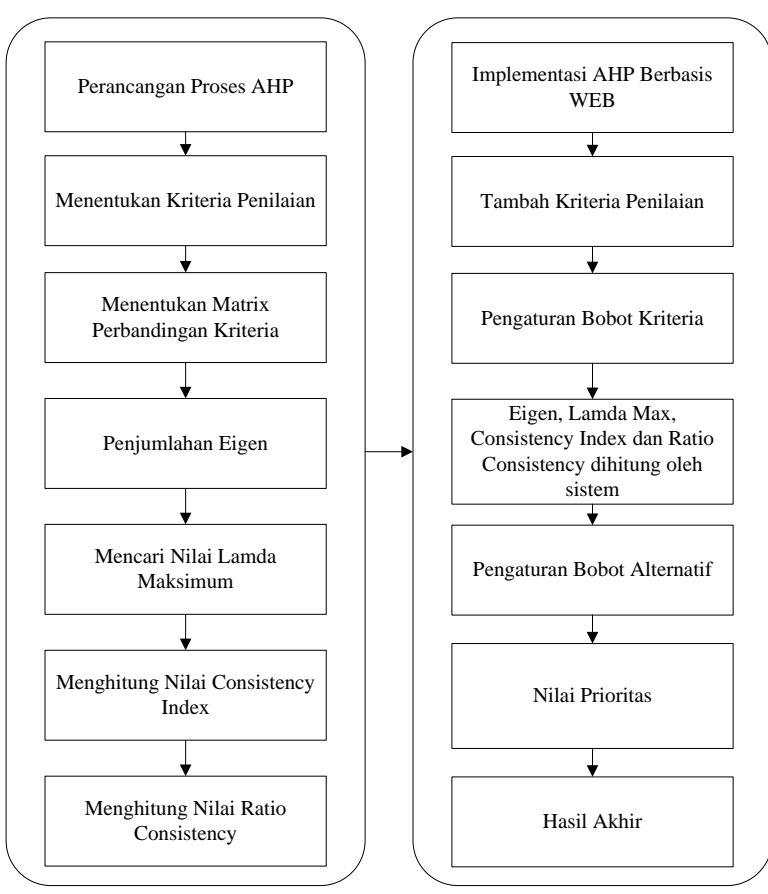

Gambar 1. Urutan Eksperiman Penelitian

Perancangan proses AHP dimulai dengan menentukan kriteria penilaian dalam penentuan perekrutan petugas keamanan. Kriteria perekrutan mengacu pada Peraturan Kepala Kepolisian Republik Indonesia dengan kriteria kesapmataan dan psikotes (Sutanto, 2007). Setelah kriteria ditentukan maka, matrix perbandingan kriteria juga dapat diselesaikan. Selanjutnya proses sesuai urutan pada proses AHP yaitu penjumlahan eigen, mencari nilai lamda maksimum, menghitung nilai consitency dan menghitung nilai ratio consistency.

Urutan di atas merupakan perhitungan bersifat manual. Pada penelitian ini AHP akan diimplementasikan berbasis website. Sehingga urutan manual dapat diimplementasikan pada sistem.

\section{Hasil dan Pembahasan}

Hasil dan pembahasan memuat perancangan proses AHP dan implementasi AHP berbasis WEB yang akan dijelaskan pada subbab berikutnya. 


\subsection{Perancangan Proses AHP}

Perancangan proses AHP disesuaikan dengan tahapan-tahapan pada proses AHP.

1) Menentukan Kriteria Penilaian

Kriteria penilaian sesuai dengan disebutkan di atas berumber dari Peraturan Kepala Kepolisian Republik Indonesia. Kriterianya adalah:
a. Tingkat Pendidikan (TP)
b. Nilai Kesapmataan (NK)
c. Nilai Psikotes (NP)
d. Hasil Wawancara

2) Menentukan Matrix Perbandingan Kriteria

Kriteria yang telah ditentukan akan dibandingan nilai kepentingan setiap kriteria tersebut.

Tabel 1 Matrix Perbandingan Kriteria

\begin{tabular}{|c|c|c|c|c|}
\cline { 2 - 5 } \multicolumn{1}{c|}{} & TP & NK & NP & HW \\
\hline TP & 1 & 3 & 3 & 5 \\
\hline NK & 0,33 & 1 & 1,00 & 3 \\
\hline NP & 0,33 & 1,00 & 1 & 3 \\
\hline HW & 0,20 & 0,33 & 0,33 & 1 \\
\hline Jumlah & 1,87 & 5,33 & 5,33 & 12,00 \\
\hline
\end{tabular}

Dari tabel di atas dijelaskan perbandingan jika bernilai 1 maka memiliki nilai sama penting dan bernilai 3 maka memiliki nilai sedikit lebih penting. Sedangkan bernilai 5 miliki nilai lebih penting.

Dari perbandingan di atas normalisasi matrix perbandingan.

Tabel 2 Normalisasi Matrix Perbandingan

\begin{tabular}{|c|c|c|c|c|c|}
\cline { 2 - 6 } \multicolumn{1}{c|}{} & TP & NK & NP & HW & Jumlah \\
\hline TP & 0,54 & 0,56 & 0,56 & 0,42 & 2,08 \\
\hline NK & 0,18 & 0,19 & 0,19 & 0,25 & 0,80 \\
\hline NP & 0,18 & 0,19 & 0,19 & 0,25 & 0,80 \\
\hline HW & 0,11 & 0,06 & 0,06 & 0,08 & 0,32 \\
\hline Jumlah & 1,00 & 1,00 & 1,00 & 1,00 & \\
\hline
\end{tabular}

\section{3) Penjumlahan Eigen}

Untuk menghitung nilai eigen merupakan penjumlahan dari setiap nilai kolom dibagi jumlah kriteria hasil terlihat pada tabel berikut.
Tabel 3 Hasil Penjumlah Vektor Eigen

\begin{tabular}{|c|c|c|}
\cline { 2 - 3 } \multicolumn{1}{c|}{} & Jumlah & Eigen \\
\hline $\mathrm{TP}$ & 2,08 & 0,52 \\
\hline $\mathrm{NK}$ & 0,80 & 0,20 \\
\hline $\mathrm{NP}$ & 0,80 & 0,20 \\
\hline $\mathrm{HW}$ & 0,32 & 0,08 \\
\hline
\end{tabular}

Dari tabel di atas dapat ditentukan vektor eigen sebagai berikut.

Tabel 4 Vektor Eigen

\begin{tabular}{|c|c|c|c|c|c|c|}
\cline { 2 - 7 } \multicolumn{1}{c|}{} & TP & NK & NP & HW & JLH & Prioritas \\
\hline TP & 0,52 & 0,60 & 0,60 & 0,39 & 2,12 & 4,08 \\
\hline NK & 0,17 & 0,20 & 0,20 & 0,24 & 0,81 & 4,04 \\
\hline NP & 0,17 & 0,20 & 0,20 & 0,24 & 0,81 & 4,04 \\
\hline HW & 0,10 & 0,07 & 0,07 & 0,08 & 0,32 & 4,02 \\
\hline
\end{tabular}

Untuk menentukan prioritas dengan cara membagikan jumlah nilai vektor eigen dengan nilai eigen.

4) Mencari Nilai $\lambda$ Max

Untuk mencari nilai lamda maksimum yaitu dengan menjumlahkan hasil prioritas dibagi jumlah kriteria

$$
\begin{aligned}
\lambda \operatorname{Max} & =\frac{(4,08+4,04+4,04+4,02)}{4} \\
& =4,04
\end{aligned}
$$

\section{5) Menghitung Nilai Consistency Index}

Untuk menghitung nilai consistencty index dengan ketentuan lamda maksimus dikurang jumlah kriteria dibagi jumlah kriteria dikurang satu.

$$
\begin{aligned}
\mathrm{CI} & =\frac{(\lambda \max -4)}{(4-1)} \\
& =\frac{(4,04-4)}{(4-1)} \\
& =\frac{0,04}{3} \\
& =0,015
\end{aligned}
$$

6) Menghitung Nilai Ratio Consistency

Selanjutnya menghitung nilai rasio konsistensi (CR), untuk melakukan pengujian konsistensi ini kita harus merujuk pada tabel Random Index yang sudah ditetapkan pada AHP dengan nilai random index ke-4 adalah 0,90.

Perhitungan didapat dari hasil bagi consistency index dengan random index ke-4. Jika 
hasil rasio consistency lebih kecil dari 0,1 maka nilai rasio consistency dianggap konsisten.

$$
\begin{array}{ll}
\mathrm{CR} & =\frac{0,015}{0,90} \\
\mathrm{CR} & =0,016 \text { (Konsisten) }
\end{array}
$$

\subsection{Implementasi AHP Berbasis WEB}

Sesuai dengan tahapan proses AHP di atas pada pembahan implementasi AHP berbasis web disesuaikan dengan aturan tersebut. Namun dalam proses perhitungan aplikasi akan menghitung berdasarkan sistem yang telah disesuaikan algoritmanya. Hasil implementasinya adalah sebagai berikut:

1. Tambah Kriteria Penilaian

Pada Aplikasi dapat diatur kriteria yang akan dijadikan syarat untuk perekrutan terlihat pada Gambar 1 berikut.

\section{Data Kriteria}

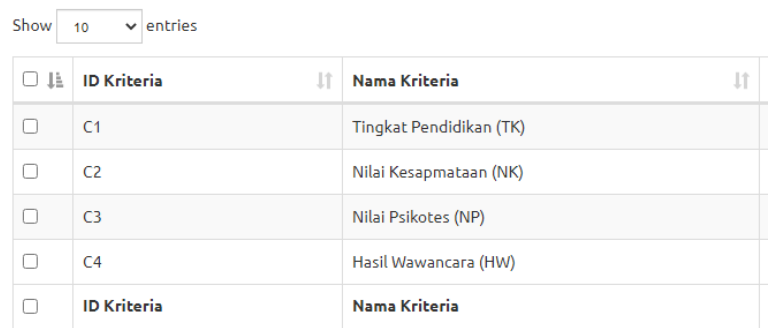

Gambar 1. Tambah Kriteria Penilian

2. Pengaturan Bobot Kriteria

Pengaturan bobot kriteria didapat dari pengaturan skala penilian prioritas sesuai Gambar 2.
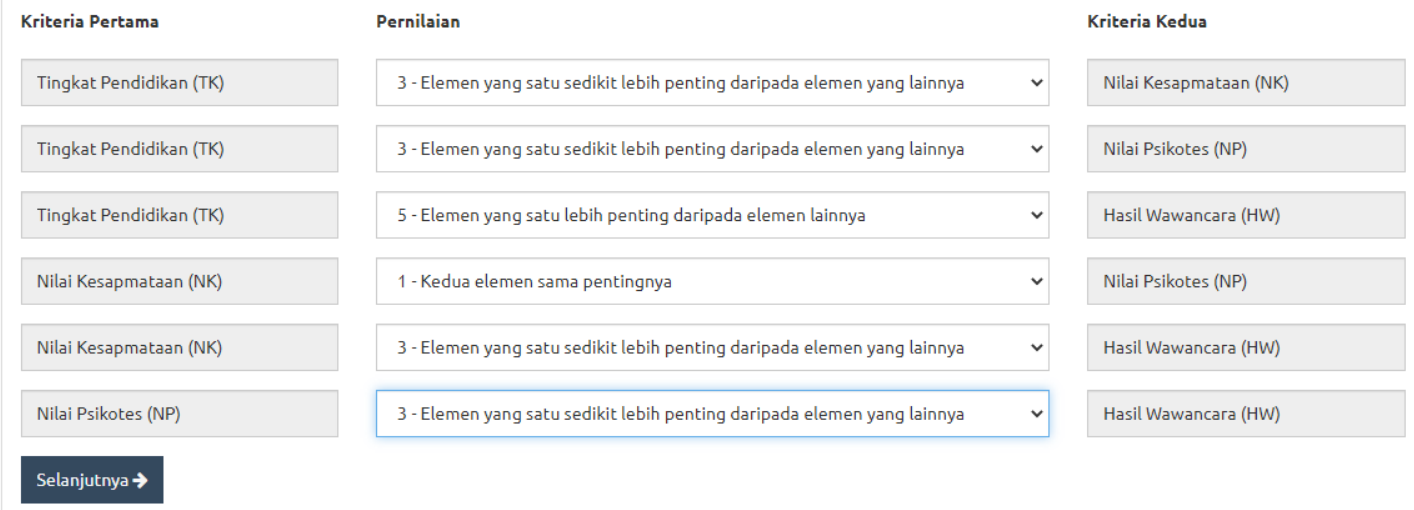

Gambar 2. Skala Penilian Prioritas

3. Perhitungan Eigen, $\lambda$ Max, Consistency Index dan Consistency Ratio
Hasil perhitungan tersebut dilakukan secara otomatis oleh aplikasi stelah skala penilian prioritas

\begin{tabular}{|c|c|c|c|c|c|c|}
\hline 2. Perbandingan & Tingkat Pendidikan (TK) & Nilai Kesapmataan (NK) & Nilai Psikotes (NP) & Hasil Wawancara (HW) & Jumlah & Prioritas \\
\hline Tingkat Pendidikan (TK) & 0.5357 & 0.5625 & 0.5625 & 0.4167 & 2.0774 & 0.5193 \\
\hline Nilai Kesapmataan (NK) & 0.1786 & 0.1875 & 0.1875 & 0.2500 & 0.8036 & 0.2009 \\
\hline Nilai Psikotes (NP) & 0.1786 & 0.1875 & 0.1875 & 0.2500 & 0.8036 & 0.2009 \\
\hline Hasil Wawancara (HW) & 0.1071 & 0.0625 & 0.0625 & 0.0833 & 0.3155 & 0.0789 \\
\hline
\end{tabular}
ditentukan terlihat pada Gambar 3 di bawah ini.

Gambar 3. Nilai Eigen

Terlihat pada Gambar 3 nilai eigen adalah untuk TK $(0,5193)$, NK $(0,2009)$, NP $(0,2009)$ dan HW $(0,0789)$. Setelah nilai eigen diperoleh maka aplikasi juga secara otomatis akan menghitung nilai vektor eigen dan $\lambda$ Max terlihat pada Gambar 4 di bawah ini. 


\begin{tabular}{|l|l|l|l|l|}
\hline 3.Penjumlahan (Eigen Vektor) & Tingkat Pendidikan (TK) & Nilai Kesapmataan (NK) & Nilai Psikotes (NP) & Hasil Wawancara (HW) \\
\hline Tingkat Pendidikan (TK) & 0.5193 & 0.6027 & 0.6027 & 0.3943 \\
\hline Nilai Kesapmataan (NK) & 0.1731 & 0.2009 & 0.2009 & 0.2366 \\
\hline Nilai Psikotes (NP) & 0.1731 & 0.2009 & 0.2009 & 0.2366 \\
\hline Hasil Wawancara (HW) & 0.1039 & 0.0670 & 0.0670 & 0.8115 \\
\hline
\end{tabular}

Gambar 4. Vektor Eigen

\begin{tabular}{|l|l|l|l|}
\hline 4.Perhitungan $\lambda$ Max & Jumlah & Prioritas & Hasil \\
\hline Tingkat Pendidikan (TK) & 2.1190 & 0.5193 & 4.0802 \\
\hline Nilai Kesapmataan (NK) & 0.8115 & 0.2009 & 4.0395 \\
\hline Nilai Psikotes (NP) & 0.8115 & 0.2009 & 4.0395 \\
\hline Hasil Wawancara (HW) & 0.3167 & 0.0789 & 4.0151 \\
\hline Rata-rata & & 4.0436 & \\
\hline
\end{tabular}

Gambar 5. Nilai $\lambda \operatorname{Max}$

Nilai $\lambda$ Max pada Gambar 5 adalah 4,0436, setelah diperoleh nilai tersebut maka ditentukan nilai consistency index dan consistency rasio terlihat pada Gambar 6 di bawah ini.

\begin{tabular}{|l}
\hline N (kriteria) \\
\hline Hasil Akhir ( $\mathrm{A}$ Maks) \\
\hline IR \\
\hline $\mathrm{Cl}$ \\
\hline $\mathrm{CR}$ \\
\hline Konsistensi (CR harus $<0.1)$ \\
\hline
\end{tabular}

Hasil consistency index yang dihitung melalui aplikasi adalah 0,0145 dan nilai consistency ratio adalah 0,0161 . Hasil nilai tersebut sesuai dengan perhitungan proses AHP yang dilakukan secara manual.

\section{Pengaturan Bobot Alternatif}

Alternatif merupakan calon petugas keamanan dalam hal ini sistem akan menguji 3 (tiga) calon petugas keamanan yang akan dilakukan secara sistem. Data diperoleh pada masing-masing alternatif terlihat pada tabel berikut.

Tabel 5 Data Alternatif

\begin{tabular}{|l|l|l|l|l|l|}
\hline No & Nama & TP & NK & NP & HW \\
\hline 1. & Adi Satrio & SMP & 88 & 86 & 83 \\
\hline 2. & Boy Sandi & SMA & 80 & 75 & 85 \\
\hline 3. & Jimi Suparno & SMP & 84 & 80 & 85 \\
\hline
\end{tabular}

Setelah data diperoleh bobot alternatif dapat disesuaikan dengan sistem terlihat pada gambar berikut.

$\begin{array}{llll}\text { Tingkat Pendidikan (TK) } & \text { Adi Satrio } & \text { Boy Sandi } & \text { Jimi Suparno } \\ \text { Adi Satrio } & 1 & 0,33 & 1 \\ \text { Boy Sandi } & 3 & 1 & 3 \\ \text { Jimi Suparno } & 1 & 0,33 & 1 \\ \text { Jumlah } & 5 & 1,66 & 5\end{array}$

Gambar 7. Bobot Alternatif TK

$\begin{array}{llll}\text { Nilai Kesapmataan (NK) } & \text { Adi Satrio } & \text { Boy Sandi } & \text { Jimi Suparno } \\ \text { Adi Satrio } & 1 & 3 & 3 \\ \text { Boy Sandi } & 0,33 & 1 & 0,33 \\ \text { Jimi Suparno } & 0,33 & 3 & 1 \\ \text { Jumlah } & 1,66 & 7 & 4,33\end{array}$

Gambar 8. Bobot Alternatif NK

$\begin{array}{llll}\text { Nilai Psikotes (NP) } & \text { Adi Satrio } & \text { Boy Sandi } & \text { Jimi Suparno } \\ \text { Adi Satrio } & 1 & 3 & 3 \\ \text { Boy Sandi } & 0,33 & 1 & 1 \\ \text { Jimi Suparno } & 0,33 & 1 & 1 \\ \text { Jumlah } & 1,66 & 5 & 5\end{array}$

Gambar 9. Bobot Alternatif NP 


$\begin{array}{llll}\text { Hasil Wawancara }(\mathrm{HW}) & \text { Adi Satrio } & \text { Boy Sandi } & \text { Jimi Suparno } \\ \text { Adi Satrio } & 1 & 0,33 & 0,33 \\ \text { Boy Sandi } & 3 & 1 & 0,33 \\ \text { Jimi Suparno } & 3 & 3 & 1 \\ \text { Jumlah } & 7 & 4,33 & 1,66\end{array}$

Gambar 10. Bobot Alternatif HW

\section{Nilai Prioritas}

Nilai prioritas dari masing-masing uji terlihat pada gambar berikut.

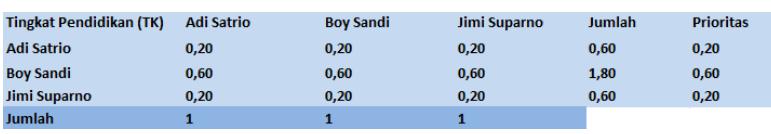

Gambar 11. Prioritas TK

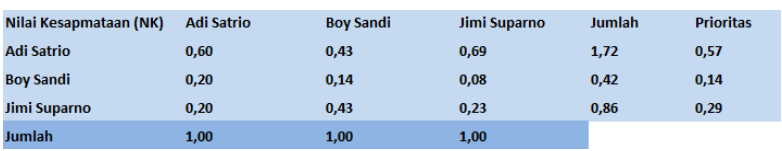

Gambar 12. Prioritas NK

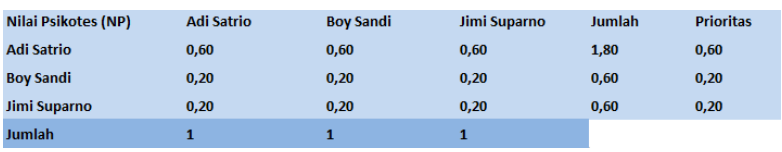

Gambar 13. Prioritas NP

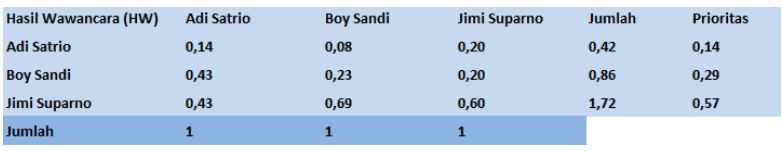

Gambar 14. Prioritas HW

\section{Hasil}

Hasil akhir merupakan perhitungan penjumlahan matrix dengan nilai kriteria.

$\begin{array}{llllll} & \text { TK } & \text { NK } & \text { NP } & \text { HW } & \text { Hasil } \\ \text { Nilai Kriteria } & \mathbf{0 , 5 0} & \mathbf{0 , 2 0} & \mathbf{0 , 2 0} & \mathbf{0 , 0 8} & \\ \text { Adi Satrio } & \mathbf{0 , 2 0} & \mathbf{0 , 5 7} & \mathbf{0 , 6 0} & \mathbf{0 , 1 4} & \mathbf{0 , 3 5} \\ \text { Boy Sandi } & \mathbf{0 , 6 0} & \mathbf{0 , 1 4} & \mathbf{0 , 2 0} & \mathbf{0 , 2 9} & \mathbf{0 , 4 0} \\ \text { Jimi Suparno } & \mathbf{0 , 2 0} & \mathbf{0 , 2 9} & \mathbf{0 , 2 0} & \mathbf{0 , 5 7} & \mathbf{0 , 2 5}\end{array}$

Gambar 15. Hasil Akhir

Terlihat pada gambar di atas bahwa hasil Boy Sandi merupakan tertinggi. Dari hasil tersebut dapat dikatakan metode AHP dapat menyelesaikan masalah perekrutan yang masih konvensional dengan nilai-nilai yang terlihat secara tranparan.

\section{Kesimpulan}

Setelah melakukan melakukan proses AHP manual dapat terlihat memiliki nilai yang sama dengan proses AHP berbasis WEB. Sehingga uji nilai pada sistem dapat digunakan. Dari hasil perhitungan akhir Boy Sandi merupakan nilai tertinggi. Dari hasil uji coba dengan nama di atas dapat disimpulkan metode AHP dapat menyelesaikan masalah perekrutan secara konvensional dengan menunjukkan nilai-nilai secara tranparansi. Metode AHP juga memiliki dapat menyelesaikan prioritas dari nilai yang terpenting dari perekrutan tersebut.

\section{Daftar Pustaka}

Badi, I., \& Abdulshahed, A. (2019). Ranking the Libyan airlines by using Full Consistency Method (FUCOM) and Analytical Hierarchy Process (AHP). Operational Research in Engineering Sciences: Theory and Applications, 2(1), 1-14. https://doi.org/10.31181/oresta1901001b

Cahyapratama, A., \& Sarno, R. (2018). Application of Analytic Hierarchy Process (AHP) and Simple Additive Weighting (SAW) methods in singer selection process. 2018 International Conference on Information and Communications Technology, ICOIACT 2018, 2018-Janиa(Mcdm), 234-239. https://doi.org/10.1109/ICOIACT.2018.8350707

Handayani, R. I., \& Muzakir, A. (2018). Sistem Pendukung Keputusan Penerimaan Karyawan Dengan Menggunakan Metode Analytical Hierarchy Process (AHP) Studi Kasus : PT. Virtus Venturama. Jurnal Pilar Nusa Mandiri, 14(1), 4348. https://doi.org/10.1007/s11276-006-6154-9

Harefa, K. (2020). Sistem Pendukung Keputusan Kelayakan Pemberian Pinjaman dengan Metode Analytical Hierarchy Process (AHP) dan Simple Additive Weighting (SAW). Jurnal Informatika Universitas Pamulang, 5(2), 136-145. https://doi.org/10.32493/informatika.v5i2.3714

Khalil, N., Kamaruzzaman, S. N., \& Baharum, M. R. (2016). Ranking the indicators of building performance and the users' risk via Analytical Hierarchy Process (AHP): Case of Malaysia. Ecological Indicators, 71(July), 567-576. https://doi.org/10.1016/j.ecolind.2016.07.032

Mathiyazhagan, K., Diabat, A., Al-Refaie, A., \& Xu, L. (2015). Application of analytical hierarchy process to evaluate pressures to implement green supply chain management. Journal of Cleaner Production, 107(October 2018), 229-236. https://doi.org/10.1016/j.jclepro.2015.04.110

Mutholib, A., \& Febrina, S. (2017). Penerapan Metode Analytical Hierarchy Process (AHP) pada Aplikasi Pendukung Keputusan Seleksi Karyawan Unicharm Indonesia. Justit Umj, 6(3), 21-26.

Rianto, B. (2016). Sistem Pendukung Keputusan Penerimaan Karyawan Menggunakan Metode Analytical Hierarchy Process ( AHP ) Studi Kasus: RB . Nilam Sari Tembilahan. Sistem Pendukung Keputusan Penerimaan Karyawan Menggunakan Metode Analytical Hierarchy Process ( AHP ) Studi Kasus : RB . Nilam Sari Tembilahan, 2(2), 29-38. 
Salah, M., Samra, S. A., \& Hosny, O. (2016). Analytical hierarchy process decision support system (AHPDSS) for trenchless technology. ISARC 2016 33 rd International Symposium on Automation and Robotics in Construction, (July), 1-9. https://doi.org/10.22260/isarc2016/0001

Sasongko, A., Astuti, I. F., \& Maharani, S. (2017). Pemilihan Karyawan Baru Dengan Metode AHP (Analytic Hierarchy Process). Informatika Mulawarman: Jurnal Ilmiah Ilmu Komputer, 12(2),

88-93.
Siregar, Y. H., \& Rahayu, S. (2018). Sistem Pendukung Keputusan Pemilihan Menu Makanan bagi Anak dengan Metode Analitycal Hierarchy Process (AHP). Jurnal Teknologi Informasi, 2(1), 24-31. https://doi.org/10.36294/jurti.v2i1.404

Sutanto. (2007). Sistem Manajemen Pengamanan Organisasi, Perusahaan dan/atau Instansi/ Lembaga Pemerintah, PERKAP NO 24 TAHUN 2007. https://doi.org/10.30872/jim.v12i2.650 